\title{
Innovation and Knowledge Sharing Across Professional Boundaries: Political Interplay between Boundary Objects and Brokers
}

\author{
Chris Kimble, Corinne Grenier and Karine Goglio-Primard
}

\begin{abstract}
The article examines the process of innovation and knowledge sharing from a perspective that focuses on the influence that local circumstances can have. In particular, it looks at the problems of knowledge sharing between groups of professionals. It presents a comparative analysis of two studies, one involving two groups of IT professionals; the other a network of healthcare professionals. The data was collected in two sets. The first set consisted of the results from two earlier, independent studies; the second was collected specifically for this article. We investigate the role played by boundary objects and brokers. Through an analysis of the interplay between boundary object and broker, we uncover the dynamics of the innovation process and show that the role played by the broker can be political. We identify two strategies that are used by brokers in the selection of a boundary object. The first is directed towards achieving a balance between the actors involved and the second is directed towards controlling their activities. We conclude by suggesting that other researchers should also consider the interplay between broker and boundary object when examining cross boundary knowledge sharing.
\end{abstract}

\section{Introduction}

It is now received wisdom that innovation stems from collaboration and knowledge sharing across professional or organizational boundaries. Conway (1995) traces the idea back to the 1950s; Teigland and Wasko (2003) claim the idea originated in the 1960s; Henderson (1990) draws on the literature from the 1970s. However, whatever its origin, the idea that innovation requires collaboration across boundaries is now well established (Fagerberg, Mowery, \& Nelson, 2005).

The majority of the literature dealing with this area tends towards what Tsoukas (1996) describes as a taxonomic approach: seeking to discover global, or at least generic, solutions for effective knowledge sharing. These often attempt to formulate more or less complete descriptions of the different types of knowledge involved and to identify the specific conditions that facilitate their exchange. Such approaches are frequently based on macro level, multifirm surveys and tend to view knowledge sharing as a continuous process (Holsapple \& Joshi, 2000; Hansen, 2002; Bock, Zmud, Kim, \& Lee, 2005; Chen \& Huang, 2007). The spread of electronic communication (Coakes, Coakes, \& Rosenberg, 2008) and notions such as the resource-based view of the firm (Wernerfelt, 1984; Grant, 1996) have also contributed to the popularity of this view.

Tsoukas (1996; 2002) however claims that this approach is fundamentally flawed; quoting Boden (1994) he argues that the structures that shape how knowledge is shared are always and inevitably influenced by "immediate circumstances and local agendas" (Boden, 1994, p. 18). He argues instead for a view of knowledge that is dispersed with no single actor in a position to formulate rules or principles to determine what knowledge should be shared. This approach tends to view knowledge sharing as an episodic rather than a continuous process. Where categories and taxonomies exist, "The stability of their meanings is precariously maintained" (Tsoukas \& Chia, 2002, p. 573): they are stable enough to be consistently deployed, but are always transient, local and open to negotiation.

C. Kimble, C. Grenier and K. Goglio-Primard Innovation and knowledge sharing across professional boundaries: Political interplay between boundary objects and brokers. International Journal of Information Management, 30(5), 2010, pp. 437 - 444. DOI: 10.1016/j.ijinfomgt.2010.02.00 
Studies that examine collaboration and knowledge sharing from this perspective have received less attention in the literature and tend to be long-term ethnographic studies that place more emphasis on group dynamics and organizational politics. Blacker and McDonald (2000) provide one such example. Taking an action research approach, they describe the problems of building and maintaining an understanding between a team of researchers and the company they are investigating in the face of the changing objectives and boundaries of both. Engeström's work on activity theory also provides some examples of this type of approach, for example when he describes the problems faced by teams of doctors in Finnish hospitals (Engeström, Engeström, \& Vähäaho, 1999; Engeström, 2001).

The goal of this article is to make a further contribution to this literature through an analysis of the issues that arise when groups of professionals from different organizations work together to achieve a collective goal; it does this through examining the findings from two independent case studies. Our approach uses boundary objects (Star \& Griesemer, 1989) and brokers (Wenger, 1998) to track the ways in which groups manage the exchange of knowledge across their respective professional boundaries. In a departure from most other studies using boundary objects and brokers, we also examine the political interplay between boundary object and broker to reveal the influence of what Boden terms "immediate circumstances and local agendas" on this process.

\section{Innovation and knowledge sharing across boundaries}

Perhaps paradoxically, the root of the problem of effective cross boundary knowledge sharing is also what makes it of value. The knowledge within a group tends to reflect its own norms and preoccupations; this makes it unlikely that the group will generate novel ideas on its own. To do this a group needs the stimulus of fresh ideas and new information from outside. However, this exchange of knowledge is not without its difficulties.

In general terms, if one group does not share the other's world view, how can communication between the two ever, in Clark and Brennan's (1991) terms, be grounded? If these groups exist in an environment that is itself changing, how much more difficult will the problem be? Finally, the more radical the innovation, the greater will be the potential problems of the redistribution of power across boundaries (Christensen, Bohmer, \& Kenagy, 2000). Cohesive groups, such as professional networks, pose a further set of problems.

Groups of professionals readily share knowledge related to their profession within the network but, for political and professional reasons, do not share this knowledge with outsiders (Teigland \& Wasko, 2003). Within such networks, informal meetings and working groups may be established to learn and share knowledge and provide actors with a space to compare professional practice. Even if they are not named as such, these often exhibit many of the features of Communities of Practice (Wenger, 1998): groups that Swan, Scarbrough and Robertson (2002) and Hislop (2003) observe can also inhibit the sharing of knowledge across boundaries.

Clearly, the sharing of knowledge across professional boundaries is both important and problematical. The notions of brokers (Wenger, 1998) and boundary objects (Star \& Griesemer, 1989) are widely cited as providing two possible channels through which such epistemically and politically distinct groups can communicate.

\subsection{Brokers}

Brokers are members of multiple communities and are able to make effective connections between them; they make co-ordination possible by opening up new possibilities for learning

C. Kimble, C. Grenier and K. Goglio-Primard Innovation and knowledge sharing across professional boundaries: Political interplay between boundary objects and brokers. International Journal of Information Management, 30(5), 2010, pp. 437 - 444. DOI: 10.1016/j.jinfomgt.2010.02.00 
and exchange (Brown \& Duguid, 1998). The broker's role is essentially that of an interlocutor: to help other actors transfer, translate or transform the meanings encountered during joint activities (Carlile, 2004). Wenger describes it in the following way:

"The job of brokering is complex. It involves processes of translation, coordination and alignment between perspectives. It requires enough legitimacy to influence the development of a practice ... it also requires the ability to link practices by facilitating transactions between them and to cause learning by introducing into a practice, elements of another." (Wenger, 1998, p 109)

A broker translates knowledge created in one group into the language of another so that the new group can integrate it into its cognitive portfolio. To do this, brokers must be able to manage the relations between individuals as well as act as translators.

The broker's role is a delicate balancing act. To be effective brokers need to have authority within all of the groups to which they belong. They need to be able to evaluate the knowledge produced by the different groups and to earn the trust and respect of the various parties involved. Over time, the broker's activities may lead to the development of a repertoire of shared resources such as rules, procedures and the boundary objects used by the group.

\subsection{Boundary Objects}

Like brokers, boundary objects are also concerned with communication between communities, although their role is more indirect. The term originates with Star and Griesemer's (1989) study of Berkeley's Museum of Vertebrate Zoology where they describe a boundary object as "an object that lives in multiple social worlds and which has different identities in each" (Star \& Griesemer, 1989, p 409).

Boundary objects are artefacts that link different sets of diverse interests; they are the physical or virtual entities that allow groups to coalesce and form stable, if transitory, working relationships. They allow coordination without consensus or shared goals, as boundary objects permit an actor's local understanding to be reframed in the context of a wider collective activity (Bechky, 2003). When different groups collaborate on a common task, some form of local agreement is necessary for the work to proceed. As the work progresses, these temporary local agreements are subject to negotiation and re-negotiation; new understandings are forged, new ideas generated and new accommodations made as the groups interact with each other.

Boundary objects are often technologies, although they can be drawings, sets of rules, research projects or documents. Kimble and Hildreth (2005), for example, describe how a planning document that was originally designed for internal use within the UK core of a transnational community of practice became, initially, a boundary object between the UK and American cores and later between the community of practice and the functional groups that surrounded it. They describe how:

"During discussions around the document, other new and innovative ideas would often be triggered; as well as identifying projects already listed on the document, new ideas emerged that could form the basis for further participation." (Kimble \& Hildreth, 2005, p 108)

Carlile (2002) argues that boundary objects have a particular role to play in supporting the different forms of coordination found in collaborative working. When a situation is familiar and routine, a simple boundary object, perhaps only a single word, is all that is needed for a group

C. Kimble, C. Grenier and K. Goglio-Primard Innovation and knowledge sharing across professional boundaries: Political interplay between boundary objects and brokers. International Journal of Information Management, 30(5), 2010, pp. 437 - 444. DOI: 10.1016/j.ijinfomgt.2010.02.00 
to coordinate its activities. He terms this syntactic coordination, effectively a simple process of information transfer. As complexity increases, actors need to establish common meanings that are shared by everybody in the group. Here the boundary object needs greater informational richness in order to support what Carlile terms semantic coordination, a process involving some degree of translation. Finally, in novel situations that involve a degree of negotiation and compromise, a boundary object needs to be flexible enough to allow what he terms pragmatic coordination, a process involving change or transformation. This form of coordination is the most difficult to achieve as change can be costly if the actors have a stake in the established way of doing things. Carlile (2004) also recognizes the political nature of these processes, as the positions held by actors can be divergent and contradictory.

\section{A comparative analysis of two cases}

As we have seen, although the link between knowledge sharing and innovation is widely recognized, the sharing of knowledge can be problematical. The goal of this article is to contribute to the literature on knowledge sharing through an analysis of the issues that arise when groups of professionals work together. In particular, we wish to examine the dynamics and politics of knowledge sharing in such groups. In order to further our understanding of this process, our study will depart from others in this area and set out to examine the interplay between boundary object and broker to expose the effect of political and contextual factors on this process.

\subsection{Methodology}

The data for our studies came from two separate cases. The first was a group of IT professionals from different companies in a French science park who collaborated to build a Content Management System; the second was a series of innovations produced by a pluridisciplinary network of heath care professionals in a medium-sized French city. In both cases, the data was collected in two sets that covered a similar period.

The first set of data consisted of two independent studies that had been carried out by two of the authors in pursuit of their own individual research interests. The second set of data was collected by the same two authors who, in order to complete the comparative analysis presented in this article, returned to the field and re-interviewed key actors to gain a better understanding of their role (e.g. as broker) and the role of certain artefacts (e.g. boundary objects).

In particular, we were interested in the mechanisms by which the boundary objects were chosen, the different types of boundary objects that were deployed and the role of the broker in terms of their legitimacy and autonomy within the groups. All of the actors involved were interviewed several times at different points in the process; the interviews lasted from 30 to 90 minutes. The two data sets are summarized in Table 1 below.

The analysis followed what Denzin and Lincoln (2000) describe as a moderate inductive approach. The set of data from the first independent studies was re-used and, together with the set of data from second targeted study, was re-analyzed using a single set of questions that related to the process of innovation and the role of boundary object and broker (Thome, 2004). Throughout the analysis, we followed the general principles outlined in Miles and Huberman's (1994) methodological framework: data reduction, coding and analysis based on codes created from a review of the literature and emergent codes created during analysis.

C. Kimble, C. Grenier and K. Goglio-Primard Innovation and knowledge sharing across professional boundaries: Political interplay between boundary objects and brokers. International Journal of Information Management, 30(5), 2010, pp. 437 - 444. DOI: 10.1016/j.ijinfomgt.2010.02.00 


\begin{tabular}{|c|c|c|}
\hline & Content Management System & Emerging Healthcare Network \\
\hline $\begin{array}{l}\text { Period of collection for the } \\
\text { first data set }\end{array}$ & From 2003 to 2006 & From 2002 to 2007 \\
\hline $\begin{array}{l}\text { Number and categories of } \\
\text { actors interviewed }\end{array}$ & $\begin{array}{l}20 \text { software engineers ( } 8 \text { from firm } \\
\text { A and } 12 \text { from Firm B), } 2 \text { e- } \\
\text { business managers and } 8 \text { sales } \\
\text { engineers ( } 3 \text { from Firm } A \text { and } 5 \\
\text { from Firm B), the system } \\
\text { administrator who acted as a } \\
\text { broker, the President of the Sophia } \\
\text { Antipolis association and the } \\
\text { person in charge of supervising the } \\
\text { cluster dealing with innovation. }\end{array}$ & $\begin{array}{l}\text { The number varied from } 6 \text { (the } \\
\text { initiator of the network, some } \\
\text { physicians, a speech therapist, a } \\
\text { neurologist and a } \\
\text { neuropsychologist, including the } \\
\text { two actors acting as brokers) to } \\
\text { more than } 15 \text { actors (additional } \\
\text { physicians, speech therapists, } \\
\text { together with the two actors acting } \\
\text { as brokers) }\end{array}$ \\
\hline $\begin{array}{l}\text { Period of collection for the } \\
\text { second data set }\end{array}$ & November 2008 & November 2008 \\
\hline $\begin{array}{l}\text { Number and categories of } \\
\text { actors interviewed }\end{array}$ & $\begin{array}{l}\text { The system administrator that acted } \\
\text { as a broker, } 5 \text { design engineers, } 4 \\
\text { sales engineers, } 2 \text { e-business } \\
\text { managers, the President of the } \\
\text { Sophia Antipolis association and } \\
\text { the person in charge of supervising } \\
\text { the cluster dealing with innovation. }\end{array}$ & $\begin{array}{l}\text { Two brokers, three physicians who } \\
\text { had been involved since } 2002 \text { and } \\
\text { one newly recruited } \\
\text { neuropsychologist. }\end{array}$ \\
\hline
\end{tabular}

\section{Table 1 Summary of the two data sets}

The first study is based on a single technological innovation where, in order to succeed, a number of boundary objects, and later a broker, needed to be deployed. This study shows clearly how boundary objects and brokers change according to immediate circumstances and the demands of the particular task in hand. The second study concerns three separate, less technologically demanding, innovations each of which use only one boundary object and broker. Here we are able to see more clearly, how boundary objects, brokers and objectives change over time.

The results of this analysis are presented below in terms of the innovations that were produced by the groups, the boundary objects they used and the role of the broker in the process. Readers should note that although both studies illustrate the demands of "immediate circumstances and local agendas" (Boden, 1994, p. 18), they differ in character and emphasis.

\subsection{Study one: the content management system}

The first study was based in the Sophia-Antipolis Science Park near Nice in the south of France. Sophia-Antipolis is sometimes described as France's 'Silicon Valley'; it brings together more than 1,300 companies in the life sciences, multimedia, computer and telecommunications sectors and several educational institutions. In 1991, a group of scientists and engineers created an association so that people working in the park could exchange ideas and knowledge more freely. Over time, the association grew into a more formalized multidisciplinary community of professionals, whose members meet to discuss their work in expert seminars.

The study focused on two groups of software engineers, one belonged to a computer services company (Company A); the other to a software development company (Company B). The engineers from Company A wanted to build a particular type of Content Management System (CMS) that would increase the value of the bids made by the commercial services division of

C. Kimble, C. Grenier and K. Goglio-Primard Innovation and knowledge sharing across professional boundaries: Political interplay between boundary objects and brokers. International Journal of Information Management, 30(5), 2010, pp. 437 - 444. DOI: 10.1016/j.jinfomgt.2010.02.00 
that company. However, to do this, they needed to work with a second group of engineers in Company B. Company B had already designed and built a CMS but wanted to improve its functionality by using it in different application areas. Both companies were independent Business Units that sold and marketed software solutions, and both had a network of local offices in France. Similarly, both groups of engineers had professional skills and expertise in their own right, both had specific knowledge that the other needed, but neither had knowledge of the other's practices or working methods. The principal actors and their motivations for the first study are shown in Table 2 below.

\begin{tabular}{|l|l|l|}
\hline \multicolumn{1}{|c|}{ Principal Actors } & \multicolumn{1}{|c|}{$\begin{array}{c}\text { Areas of expertise / } \\
\text { knowledge }\end{array}$} & \multicolumn{1}{c|}{ Motivations } \\
\hline $\begin{array}{l}\text { Eight software engineers } \\
\text { belonging to a computer } \\
\text { services company } \\
\text { (Company A) }\end{array}$ & $\begin{array}{l}\text { All the actors share the same } \\
\text { practices and have similar } \\
\text { technical expertise. }\end{array}$ & $\begin{array}{l}\text { Company A wish to appropriate } \\
\text { the functionality of the CMS built } \\
\text { by Company B to add value to } \\
\text { the bids they make to } \\
\text { customers. }\end{array}$ \\
\hline $\begin{array}{l}\text { Twelve software } \\
\text { engineers belonging to a } \\
\text { software development } \\
\text { company (Company B) }\end{array}$ & $\begin{array}{l}\text { All the actors share the same } \\
\text { practices and have similar } \\
\text { technical expertise. The actors } \\
\text { have already succeeded in } \\
\text { creating a CMS that is currently } \\
\text { in use. }\end{array}$ & $\begin{array}{l}\text { Company B wants to find new } \\
\text { applications for their existing } \\
\text { CMS and promote its use in the } \\
\text { Sophia Antipolis and beyond. }\end{array}$ \\
\hline Business Customers & $\begin{array}{l}\text { Domain knowledge of } \\
\text { semiconductors, telecom } \\
\text { services, infrastructure services. }\end{array}$ & $\begin{array}{l}\text { Customers want } \\
\text { straightforward, turnkey } \\
\text { technical solutions to their } \\
\text { problems. }\end{array}$ \\
\hline
\end{tabular}

\section{Table 2 Actors and motivations in study one}

The software engineers in companies $A$ and $B$ recognized the existence of various boundaries that would inhibit the achievement of their shared goal. The mechanism they used to overcome these was to attempt to develop a new system by co-building a web site for a customer from Company A. The success of this venture would rest on the ability of the two software companies and, to a lesser extent, the two companies and the customer, to share knowledge and expertise across boundaries.

"We would not have been able to meet the customer's expectations alone. Our cooperation with Company $B$, clearly made a difference for the customer and certainly influenced its final selection" (Manager, Company A)

The software engineers in Company A wished to use the CMS built by Company B in their own company's products. This would mean that they could provide web sites that had more functionality and were more efficient. Similarly, the engineers from Company B wanted to find new applications for their software, but lacked knowledge of other domains where it might be used.

Working together on the code for the CMS enabled both firms to begin to develop the new system and to consolidate their links with the customer. They were able to start to combine their technical and commercial expertise and to mobilize a project team to develop a solution.

The code for the CMS acted as the first boundary object and provided a degree of syntactic coordination, however, the problems of semantic coordination needed to be resolved using a different approach. In Company B, the software engineers knew each other well, worked

C. Kimble, C. Grenier and K. Goglio-Primard Innovation and knowledge sharing across professional boundaries: Political interplay between boundary objects and brokers. International Journal of Information Management, 30(5), 2010, pp. 437 - 444. DOI: 10.1016/j.ijinfomgt.2010.02.00 
closely together and observed each other's practices. This enabled them to share their experience and knowledge when developing new versions of the CMS within the company. However, when working with engineers from Company $A$,

"... it's very difficult to develop trust between two competing firms because we have strategic skills that we use for the same customers" (Engineer, Company B)

The Sophia Antipolis Association exists primarily to facilitate professional links between organizations in the Sophia Antipolis Science Park. The software engineers from companies $A$ and $B$ were able to discuss the objectives and the technical problems of the CMS with their peers from other companies, their customers and members of the research institutions through seminars and forums organized by the association. Effectively, the events organized at the science park became the second boundary object and the mechanism by which the gap between the two groups was bridged.

"... our geographic and technological proximity helped us understand each other and be committed to the project" (Manager, Company B)

The association had also developed a professional code of conduct to facilitate the inter-firm cooperation that also helped to minimize any commercial concerns that might otherwise have hindered the process.

Finally, to deal with the problems of pragmatic coordination, the two companies appointed a systems administrator from Company $\mathrm{B}$, the company that developed the original CMS, to act as an intermediary. This systems administrator effectively took on the broker's role and was required to give the final formal approval to the software created by the two groups of engineers.

"We appointed an engineer from firm $B$ to this position. His specific role consisted in validating the functionalities created by our engineers and to inform us of existing functionalities" (Software Engineer, Company A)

However, to fulfil this role he needed to be able to coordinate the activities of other actors, to translate requirements between them and, crucially, to create a space where the actors could work free from the conflicts inherent in this type of venture (Kaulback \& Bergtholdt, 2008).

Through a series of informal meetings, he created a sense of commitment between the two sets of engineers that allowed them to share their knowledge and develop a mutual understanding. In terms of his wider role, he also helped to differentiate the contribution of the two firms, which in turn made them more attractive to their respective customers. Finally, he also helped the actors to use, understand and accept the rules of the association. Through this, the actors were able to recognize other firms' complementary skills and to learn to trust each other.

Thus, in this case, the role of the two boundary objects was to enable the coordination of the activities of the groups at the syntactic and semantic level. The role of the broker focused mainly on providing legitimacy for the proposed technical solutions, and on building trust and maintaining a fair and balanced exchange between the two firms. Thus, in this case, the broker's role was to manage the relationships between the actors at the pragmatic level.

C. Kimble, C. Grenier and K. Goglio-Primard Innovation and knowledge sharing across professional boundaries: Political interplay between boundary objects and brokers. International Journal of Information Management, 30(5), 2010, pp. 437 - 444. DOI: 10.1016/j.ijinfomgt.2010.02.00 


\subsection{Study two: the healthcare network}

For many decades, different professional groups in the French health sector have set up various collective arrangements to help improve their knowledge of, and response to, sociomedical issues such as AIDS, Alzheimer's disease and drug or alcohol addiction. These collective arrangements are normally set up when a response based on a single agency proves unsatisfactory. These arrangements are often termed 'cure and care' networks. In 1996, regulations began to be introduced that created a framework for such networks and set out the conditions under which they could receive public funding.

The network in this study is dedicated to the diagnosis, cure and care of the cognitive diseases. The network started in 2001 as an informal ad-hoc group, developed and grew over time, and finally became a publicly funded network at the end of 2004. The group brought together several disparate specialist communities that represented different, and occasionally conflicting, interests. The principal actors and their motivations are shown in Table 3 below.

\begin{tabular}{|l|l|l|}
\hline \multicolumn{1}{|c|}{ Actors } & \multicolumn{1}{|c|}{$\begin{array}{c}\text { Areas of expertise / } \\
\text { knowledge }\end{array}$} & \multicolumn{1}{c|}{ Motivations } \\
\hline $\begin{array}{l}\text { Physicians (General } \\
\text { Practitioners) }\end{array}$ & $\begin{array}{l}\text { knowledge of the patient } \\
\text { and their medical history } \\
\text { but work in isolated } \\
\text { practices with no } \\
\text { specialist knowledge of } \\
\text { cognitive diseases. }\end{array}$ & $\begin{array}{l}\text { Interested in any cognitive disorder. } \\
\text { Interested in facilitating diagnosis and the follow- } \\
\text { up of the patient. } \\
\text { To enrich practice through maintaining a role in } \\
\text { the long-term follow-up of a patient. }\end{array}$ \\
\hline The Neurologist & $\begin{array}{l}\text { Has specialized } \\
\text { knowledge in } \\
\text { Alzheimer's disease. }\end{array}$ & $\begin{array}{l}\text { Interested in tools to help a neurologist make a } \\
\text { more rapid diagnosis. } \\
\text { To maintain the core role of neurologists in } \\
\text { diagnosis. }\end{array}$ \\
\hline The Gerontologist & $\begin{array}{l}\text { Knowledge of cognitive } \\
\text { disorders and other } \\
\text { pathologies in elderly } \\
\text { people. }\end{array}$ & $\begin{array}{l}\text { Interested in taking part in the diagnosis, } \\
\text { including having the right to make a diagnosis } \\
\text { instead of the neurologist. }\end{array}$ \\
\hline The Coordinator \\
(Neuropsychologist) & $\begin{array}{l}\text { No practice before the } \\
\text { emergence of the } \\
\text { network (new role and } \\
\text { new knowledge). }\end{array}$ & $\begin{array}{l}\text { To maintain a pluridisciplinary-based approach to } \\
\text { work and to coordinate practices. } \\
\text { Interested in any social intervention with patients } \\
\text { and their families. }\end{array}$ \\
\hline The Speech Therapists & $\begin{array}{l}\text { Mostly involved with } \\
\text { elderly and disabled } \\
\text { people. }\end{array}$ & $\begin{array}{l}\text { To be more involved and to be legitimized as an } \\
\text { actor that participates in the care and cure of } \\
\text { people with cognitive disorders. }\end{array}$ \\
\hline
\end{tabular}

Table 3 Actors and motivations in study two

Initially, a neurologist, some physicians, a gerontologist and a speech therapist started to meet on a monthly basis to hold 'case conferences' - collective discussions that allow different points of view to be heard and common themes to be identified. In the early stages of the network, the physicians used their own patient files for these discussions. The case conferences, which were organized by the neurologist, highlighted the need to have one tool to help physicians to quickly and simply differentiate cognitive disorders from other disorders with similar symptoms. The rapid memory test was developed in response to this need.

The neurologist, who effectively acted as a broker, arranged the network in such a way that it would focus on patients with the problems that he was skilled in diagnosing and interested in, mainly those with Alzheimer's disease.

C. Kimble, C. Grenier and K. Goglio-Primard Innovation and knowledge sharing across professional boundaries: Political interplay between boundary objects and brokers. International Journal of Information Management, 30(5), 2010, pp. 437 - 444. DOI: 10.1016/j.jinfomgt.2010.02.00 
"... thanks to [the network] I can receive in my office one patient with a richly documented file, so as to ease the making of the diagnosis" (neurologist)

The selection of patient files by physicians as boundary objects strengthened this position. The network preserved an informal but strongly institutionalized hierarchy that meant neurologists were the only ones allowed to make a diagnosis of the disease. The neurologist regulated the links between the different professional communities in such a way that he limited the opportunities for different communities to mix. In effect, he reinforced his own authority and his community's professional boundaries.

The rapid memory test was developed based on information gained from the crossing of boundaries; however, it represented little more than a means of improving the links between the work of physicians, who were able to use the test to identify possible cognitive disorders, and the neurologists, who were able to see the patient more quickly. Once the rapid memory test had been developed and training sessions in its use had begun, some physicians and speech therapists began to discuss the development of a more comprehensive tool for the assessment of Alzheimer's disease. This tool, which would allow neurologists to make a more detailed diagnosis of the disease, became the cross-disciplinary neuropsychological assessment.

Once again, the neurologist controlled the links between the professional communities, although he now had to open the discussion to speech therapists and neuropsychologists. He acted as a broker, directing the discussion and validating any proposed solution. For example, he turned down the proposal by a gerontologist, skilled in diagnosing diseases of the elderly, that gerontologists should play a role in the diagnosis process arguing,

"... dementia is not Alzheimer disease; dementia is a cognitive process of cognitive degradation. It is very different from the Alzheimer disease; the latter is much more complex. You cannot make a diagnosis of Alzheimer disease with a gerontologist diploma" (neurologist)

The gerontologist did not attend any further meetings of the network.

The development of the cross-disciplinary neuropsychological assessment was supported by the same boundary object and the same boundary hardening strategy as the previous example and achieved the same outcome for the neurologist.

"Thanks to the network, I can now concentrate on the diagnosis of the more complex cognitive cases ... the other less complex cases are examined and diagnosed by other actors" (neurologist)

However, this innovation was only made possible by an additional crossing of a professional boundary when the physicians and the speech therapists began to discuss their respective professional practices together. The actors, involved all agreed that the process was slower and more difficult than the first, as the physician's patient file did not really contain adequate information to build a more interdisciplinary form of coordination.

The coordinated patient trajectory was the third innovation produced by this network. This consisted of a comprehensive assessment that identified all the actors concerned with the care and cure of cognitive disorders, from the initial diagnosis to the follow-up social and medical care. This required the use of a different boundary object, the case files of patients 
who had already been followed-up by the network. These files contained information collected during other aspects of the network's activities. For example,

"Sometimes patients deliver to the speech-therapist or other actors, information that they would not give to their family physicians" (speech therapist)

It also required the opening of discussions to new actors with expertise in the social and medical follow-up of the patients and of their families. This innovation was made possible by a change of broker, which was dictated primarily by a change in local circumstances. The network was seeking public funding and, in order to meet the criteria to receive public funds, it had to show that the goal of the network was to coordinate the activities of all of the actors involved in the care and cure of the patient. The neurologist stepped down and a neuropsychologist took on a new and more formal role as network coordinator.

The neuropsychologist was interested in care and cure activities after the initial diagnosis had been made, and so was open to involvement of groups other than physicians and neurologists. After the coordinated patient trajectory had been developed, it was accepted that the initial diagnosis of Alzheimer's disease could be made either by a neurologist or by a gerontologist, reversing the group's previous decision.

"Thanks to the network, all various actors are now involved and each one has found his place [in the coordinated patient trajectory]" (coordinator)

This case, which covers a longer period and wider range of activities, presents a rather more complex picture than the first as here brokers, boundary objects and high-level objectives all changed over the period of the study. Consequently, this case more clearly illustrates the use of the boundary object either to control the direction of the collective action or to open a broader discussion of topics around the object.

\section{Discussion: the interplay between boundary objects and brokers}

We saw earlier that the literature on innovation and knowledge sharing describes brokers and boundary objects as channels through which epistemically distinct groups can communicate and collaborate. We adopted this general approach to examine the process by which knowledge is shared and innovations are produced at a local level.

At first sight, the boundary objects in our study simply acted as a means for transforming and transferring knowledge between groups. It appeared that it was mainly the complexity of the innovation that determined which boundary object was chosen (Carlile, 2002, 2004). The selection of the boundary object appears to be a 'technical' choice based on the level of information needed to sustain the innovation process; the broker merely acts as tertius iungens by connecting the interested parties (Obstfeld, 2005).

In the first study, the code for CMS (the first boundary object) allowed the actors to develop the concrete technical solutions that allowed them to make some initial progress with their work. Similarly, the framework and rules provided by the association (the second boundary object) allowed the actors to continue to work together in ways that would not have been possible without them. The association fostered the development of trust and commitment between the two firms, firstly because the association was itself composed of experts competence based trust - and secondly because membership of the association bound its members to a code of behaviour allowing the development of trust based on reciprocity and goodwill.

C. Kimble, C. Grenier and K. Goglio-Primard Innovation and knowledge sharing across professional boundaries: Political interplay between boundary objects and brokers. International Journal of Information Management, 30(5), 2010, pp. 437 - 444. DOI: 10.1016/j.ijinfomgt.2010.02.00 
In the second study, the patient file created by physicians (the first boundary object) allowed actors to create the first two innovations, the rapid memory test and the cross-disciplinary neuropsychological assessment, but the patient file created by the network as a whole (the second boundary object), was required to support the third innovation, the coordinated patient trajectory. Changes in the boundary object occurred when the former boundary object was no longer able to sustain the innovation process because of its inability to support a discussion that included a wider range of competences. Thus, the second boundary object was chosen specifically in order to embrace these competencies.

However, by further examining the interplay between broker and boundary object, we are able to highlight an additional dimension to the selection of the boundary object: the boundary object as a resource for actors who wish to further their own interests. Grenier (2006) suggests that the boundary objects are often chosen by the leaders of groups in accordance with the degree of diversity they are prepared to tolerate. Applying this perspective to our study reveals an additional dimension and a more complex story. We propose a 'political' interplay between boundary object and broker.

In the first case study, the two software companies were potential competitors in the same market. Using the CMS code alone laid one company open to the 'extortion' of its knowledge by the other. Consequently, the broker need to introduce a second boundary object to maintain fair and balanced cooperation. In doing so, the broker acquired a legitimacy that was beyond a simple recognition of his technical skill which allowed him to set the conditions for cooperation between companies, avoid an unbalanced appropriation of knowledge by one company from the other, and maintain a stable environment in which the work that they were all engaged in could proceed smoothly. In this example, the selection of the boundary object was a political act taken to maintain the stability of the collective that effectively allowed a new inter-firm Community of Practice to emerge based around the common goal of commercial success and the sharing of ideas on the building of a CMS.

The second study presents a slightly different picture from the first. The first broker, the neurologist, selected a boundary object that favoured the interests of his own and the physician's professional body. This strengthened his position and that of his professional community. The second broker, the neuropsychologist, also made a political choice, but for different reasons. She chose a boundary object that would reorient the network towards the social care of the patients rather than the diagnosis of diseases. She selected an object that allowed more diversity and acknowledged the value of the other actors' expertise, thus weakening the position previously established by the neurologist. Thus, in this example, the choice of boundary object was also a political act directed towards (re)defining or steering the direction of the evolution joint enterprise, by either restricting the flow of information or by giving a greater acknowledgement to the importance of other actors' expertise.

Boundary objects are particularly appropriate for this task as they have not only symbolic value but also a political message (Swan, et al., 2002). Viewed in this way, our work complements that of $\mathrm{Gal}$ et al (Gal, Yoo, \& Boland, 2004) who consider boundary objects to be a resource that can be used to transform social identities. By looking more closely at the interplay between broker and boundary object we can reveal how the selection of the boundary object can be a political act directed towards maintaining or redefining the direction of the group's activities. Using Obstfeld's terminology (Obstfeld, 2005), in these circumstances, the broker acts as tertius gaudens ("the third who benefits") rather than tertius iungens ("the third who joins").

Comparing the two cases, we see two forms of political interplay emerge: one is more collectively oriented and comes into play where a broker selects a boundary object to further

C. Kimble, C. Grenier and K. Goglio-Primard Innovation and knowledge sharing across professional boundaries: Political interplay between boundary objects and brokers. International Journal of Information Management, 30(5), 2010, pp. 437 - 444. DOI: 10.1016/j.ijinfomgt.2010.02.00 
collective goals; the other is more individually oriented, and comes into play when a broker chooses a boundary object principally to defend their own position. These two political orientations for the interplay between boundary object and broker are summarized in table 5 below

\begin{tabular}{|l|l|l|}
\hline & \multicolumn{1}{|c|}{$\begin{array}{c}\text { Collectively-oriented } \\
\text { strategy }\end{array}$} & \multicolumn{1}{|c|}{$\begin{array}{c}\text { Individually-oriented } \\
\text { strategy }\end{array}$} \\
\hline $\begin{array}{l}\text { The role of the boundary } \\
\text { object }\end{array}$ & $\begin{array}{l}\text { The boundary object functions } \\
\text { at different levels: it contains } \\
\text { both technical information and } \\
\text { offers ways to work } \\
\text { collectively. }\end{array}$ & $\begin{array}{l}\text { The boundary object is an } \\
\text { intermediary object, offering } \\
\text { mainly technical information } \\
\text { related to the innovation. }\end{array}$ \\
\hline $\begin{array}{l}\text { The interplay between broker } \\
\text { and boundary object }\end{array}$ & $\begin{array}{l}\text { The boundary object is } \\
\text { mobilized by the broker to aid } \\
\text { the exchange of information } \\
\text { and to facilitate coordination } \\
\text { between the actors in the } \\
\text { collective. }\end{array}$ & $\begin{array}{l}\text { The boundary object is } \\
\text { mobilized by the broker to } \\
\text { limit the amount of information } \\
\text { available and to define the } \\
\text { direction of the joint } \\
\text { enterprise. }\end{array}$ \\
\hline
\end{tabular}

Table 4 Political interplay between boundary object and broker

\section{Conclusions}

Innovation in groups depends on information and knowledge gained by crossing boundaries between communities of actors. This is a difficult and complex process because, for it to be successful, the actors from the different communities must first reach a shared understanding about what they are trying to do and how it might be achieved. These problems can be exacerbated when the communities of actors concerned are groups of professionals where their respective professional knowledge is what helps to define their status and is the key to their authority.

Much of the work in this area suggests that the selection of a boundary object is more or less technical in nature: a matter of choosing the right boundary object for a particular set of circumstances (Harvey \& Chrisman, 1998; Smeds \& Alvesalo, 2003). Our studies suggest that this process is more complex, dynamic and can be explicitly political in nature. We believe that this observation constitutes our first contribution to the work in this area. We therefore suggest that, in addition to simply looking at the role of the boundary object, researchers should also examine the role of a broker in its selection.

Our second contribution is to qualify this political interplay between boundary object and broker further and identify two distinct strategies by which a broker might use a boundary object. The first is directed towards achieving some form of political balance between the actors in a community and focuses on making information more available. The second is directed towards the definition or control of the overall direction of the community and is more concerned with controlling the flow of information.

We believe that by adopting this approach of examining the interplay between boundary object and broker, researchers will be able achieve a more rounded view of the dynamics of innovation and knowledge sharing, particularly in situations such as those we describe here. We believe that, in turn, this could lead to the consideration of other political dimensions in this process, such as who should be in charge of the system of brokerage, what that system should be and other issues related to what might be termed the governance of innovation.

C. Kimble, C. Grenier and K. Goglio-Primard Innovation and knowledge sharing across professional boundaries: Political interplay between boundary objects and brokers. International Journal of Information Management, 30(5), 2010, pp. 437 - 444. DOI: 10.1016/j.ijinfomgt.2010.02.00 


\section{References}

Bechky, B. A. (2003). Sharing meaning across occupational communities: The transformation of understanding on a production floor. Organization Science, 14, 312-330.

Blackler, F., \& McDonald, S. (2000). Power, mastery and organizational learning. Journal of Management Studies, 37, 833-851.

Bock, G. W., Zmud, R. W., Kim, Y. G., \& Lee, J. N. (2005). Behavioral intention formation in knowledge sharing: Examining the roles of extrinsic motivators, social-psychological forces, and organizational climate. Mis Quarterly, 29, 87-111.

Boden, D. (1994). The Business of Talk. Boston: Polity.

Brown, J. S., \& Duguid, P. (1998). Organizing Knowledge. California Management Review, 40, $90-111$.

Carlile, P. R. (2002). A Pragmatic View of Knowledge and Boundaries: Boundary Objects in New Product Development. Organization Science, 13, 442 - 455.

Carlile, P. R. (2004). Transferring, translating, and transforming: An integrative framework for managing knowledge across boundaries. Organization Science, 15, 555-568.

Chen, C. J., \& Huang, J. W. (2007). How organizational climate and structure affect knowledge management - The social interaction perspective. International Journal of Information Management, 27, 104-118.

Christensen, C. M., Bohmer, R., \& Kenagy, J. (2000). Will disruptive innovations cure health care? Harvard Business Review, 78, 102-112.

Clark, H., \& Brennan, S. (1991). Grounding in Communication. In L. B. Resnick, J. M. Levine \& S. D. Teasley (Eds.), Perspectives on Socially-Shared Cognition. (pp. 127-149).

Washington, D.C.: American Psychological Association.

Coakes, E. W., Coakes, J. M., \& Rosenberg, D. (2008). Co-operative work practices and knowledge sharing issues: A comparison of viewpoints. International Journal of Information Management, 28, 12-25.

Conway, S. (1995). Informal Boundary-Spanning Communication In The Innovation Process An Empirical-Study. Technology Analysis \& Strategic Management, 7, 327-342.

Denzin, N. K., \& Lincoln, Y. S. (2000). The Discipline and Practice of Qualitative Research. In N. K. Denzin \& Y. S. Lincoln (Eds.), The Handbook of Qualitative Research (2nd revised edition ed., pp. 1 - 28). London: Sage.

Engeström, Y. (2001). Expansive Learning at Work: toward an activity theoretical reconceptualization. Journal of Education and Work, 14, 133 - 156.

Engeström, Y., Engeström, R., \& Vähäaho, T. (1999). When the center does not hold: The importance of knotworking. In S. Chaiklin, M. Hedegaard \& U. J. Jensen (Eds.), Activity theory and social practice (pp. 345 - 374). Aarhus: Aarhus University Press.

Fagerberg, J., Mowery, D. C., \& Nelson, R. R. (2005). The Oxford handbook of innovation. In. Oxford ; New York: Oxford University Press.

Gal, U., Yoo, Y., \& Boland, R. J. (2004). The Dynamics of Boundary Objects, Social Infrastructures and Social Identities. In Sprouts: Working Papers on Information Systems (Vol. 4): Case Western Reserve University, USA.

Grant, R. (1996). Toward a Knowledge-Based Theory of the Firm. Strategic Management Journal, 17, 109 - 122.

C. Kimble, C. Grenier and K. Goglio-Primard Innovation and knowledge sharing across professional boundaries: Political interplay between boundary objects and brokers. International Journal of Information Management, 30(5), 2010, pp. 437 - 444. DOI: 10.1016/j.ijinfomgt.2010.02.00 
Grenier, C. (2006). Apprentissage de la coordination entre acteurs professionnels - le cas d'un réseau de santé. Revue Gérer et Comprendre, 83, 25 - 35.

Hansen, M. T. (2002). Knowledge Networks: Explaining Effective Knowledge Sharing in Multiunit Companies. Organization Science, 13, 232-248.

Harvey, F., \& Chrisman, N. (1998). Boundary objects and the social construction of GIS technology. Environment and Planning A, 30, 1683-1694.

Henderson, R. M., \& Clark, K. B. (1990). Architectural Innovation: The Reconfiguration of Existing Product Technologies and the Failure of Established Firms. Administrative Science Quarterly, 35, 9-30.

Hislop, D. (2003). The Complex Relations Between Communities of Practice and the Implementation of Technological Innovations. International Journal of Innovation Management, 7, 163 -188.

Holsapple, C. W., \& Joshi, K. D. (2000). An investigation of factors that influence the management of knowledge in organizations. Journal of Strategic Information Systems, 9, 235261.

Kaulback, B., \& Bergtholdt, D. (2008). Holding the Virtual Space: The Roles and

Responsibilities of Community Stewardship. In C. Kimble \& P. Hildreth (Eds.), Communities of Practice: Creating Learning Environments for Educators (Vol. 2, pp. 25-44): Information Age Publishing.

Kimble, C., \& Hildreth, P. (2005). Dualities, Distributed Communities of Practice and Knowledge Management. Journal of Knowledge Management, 9, 102 - 113.

Miles, M. B., \& Huberman, M. A. (1994). Qualitative data analysis: An expanded sourcebook (2nd ed ed.): Sage.

Obstfeld, D. (2005). Social Networks, the Tertius lungens Orientation, and Involvement in Innovation. Administrative Science Quarterly, 50, 100-130.

Smeds, R., \& Alvesalo, J. (2003). Global business process development in a virtual community of practice. Production Planning \& Control, 14, 361-371.

Star, S. L., \& Griesemer, J. R. (1989). Institutional Ecology, 'Translations' and Boundary Objects: Amateurs and Professionals in Berkeley's Museum of Vertebrate Zoology, 1907-39. Social Studies of Science, 19, 387-420.

Swan, J., Scarbrough, H., \& Robertson, M. (2002). The construction of 'communities of practice' in the management of innovation. Management Learning, 33, 477-496.

Teigland, R., \& Wasko, M. M. (2003). Integrating knowledge through information trading: Examining the relationship between boundary spanning communication and individual performance. Decision Sciences, 34, 261-286.

Thome, S. (2004). Qualitative secondary analysis. In M. S. Lewis-Beck, A. Bryman \& T. F. Liao (Eds.), The Sage Encyclopedia of Social Science Research Methods (Vol. 3): Sage.

Tsoukas, H. (1996). The firm as a distributed knowledge system: A constructionist approach. Strategic Management Journal, 17, 11-25.

Tsoukas, H., \& Chia, R. (2002). On organizational becoming: Rethinking organizational change. Organization Science, 13, 567-582.

Wenger, E. (1998). Communities of Practice: Learning, Meaning, and Identity. New York: Cambridge University Press.

Wernerfelt, B. (1984). A resource-based view of the firm. Strategic Management Journal, 5, 171-180.

C. Kimble, C. Grenier and K. Goglio-Primard Innovation and knowledge sharing across professional boundaries: Political interplay between boundary objects and brokers. International Journal of Information Management, 30(5), 2010, pp. 437 - 444. DOI: 10.1016/j.ijinfomgt.2010.02.00 